\title{
New Methods of Diagnosis and Treatment of Ophthalmic Artery Stenosis in Patients with Ischemic Central Retinal Vein Occlusions
}

\section{Lewis D Friedlander*}

Image Vision Surgery Center, 5505 Roswell RD, Atlanta GA, USA

\begin{abstract}
Introduction: The purpose of this report was to examine if correlations exist in patients with Ischemic Central Retinal Vein Occlusion syndromes and significant narrowing's of the ophthalmic arteries. Further, we wanted to see if a minimally invasive technique could accurately indicate low orbital arterial perfusion and predict which patients may benefit from cerebral angiography. By identifying proximal ophthalmic artery lesions which may contribute to retinal hypo perfusion and severe visual loss, ophthalmic artery revascularization may be a reasonable recommendation in selected cases. One patient who underwent revascularization experienced dramatic improvement in visual function and retinal morphology. If ophthalmic artery disease proves to be a relatively consistent finding in Ischemic Central Retinal Vein occlusive disease, techniques for intervention could be offered.
\end{abstract}

Methods: In nine patients with ischemic central vein occlusion who had sudden or rapidly progressive visual loss, studies of choroidal perfusion and cerebral angiography were obtained. Binocular Fundus Reflectometry was used in all patients to evaluate choroidal perfusion. OPG and ODM were also evaluated in each patient. Cerebral angiography was used with special attention to orbital filling details with use of subtraction and magnification views. In all patients other metabolic factors, lesions causing mass effect producing lesions, and cardiac factors were ruled out unusual causes of ischemic central vein occlusion syndromes. Additionally, each patient had evaluation for present or past history of ocular infections. In one of the patients who suffered from rapid progressive visual loss with a diagnosis of ischemic central retinal vein occlusion and had an identifiable focal proximal ophthalmic artery narrowing, a microsurgical bypass of the ophthalmic artery was performed to reverse hypo perfusion.

Results: All patients had a negative workup for other cardiac, metabolic and radiologic factors that could cause a picture of ischemic central retinal vein occlusion No patient had evidence of ocular infection or a past history of ocular infection. All patients had abnormalities of perfusion indicated by abnormal reflectograms on the affected side. Three of the nine patients had contralateral abnormalities of ocular perfusion according to BFR. In each of these cases arteriography indicated abnormalities of the ophthalmic artery on the opposite side that would account for the abnormal perfusion indicated by BFR. In six of the nine cases a definite focal abnormality in the proximal orbital portion of the ophthalmic artery could be identified. In the other three cases where no definite proximal obstructing lesion could be seen, clear evidence of distal diffuse arterial disease was seen. These abnormalities include abrupt narrowing of filling in the main trunk of the ophthalmic artery, slow or absent filling of the choroid blush, and nonvisualization of the ciliary or distal branches of the ophthalmic artery such as the lacrimal and supra orbital arteries. In the patient who underwent the bypass of the ophthalmic artery, dramatic and sustained improvement in visual acuity and visual fields were seen as well as resolution on ophthalmoscopy of the retinal hemorrhages and congestion.

Conclusions: Syndromes of ischemic central retinal vein occlusion that presents as sudden and severe visual loss may have significant narrowing's of the orbital ophthalmic artery which can be detected by minimally invasive technology. Binocular fundus reflectometry appears to be a sensitive indicator of low ocular perfusion and valuable to select patients for arteriography. These stenotic lesions may account significantly for decreased perfusion and may go unappreciated unless systematically searched for. Some of these lesions may be treatable by microsurgical revascularization which may result in visual improvement. Identification of a consistent in Ischemic Central Retinal Vein Occlusion syndrome would greatly expand our ability to manage this disorder. It may become helpful to correlate ocular perfusion and ophthalmic artery anatomy when assessing and classifying Ischemic Central Retinal Vein Occlusion.

Keywords: Stenotic; Reflectometry; Cardiac; Metabolic

\section{Introduction}

Ischemic central retinal vein occlusion (CRVO) remains one of the leading causes of blindness among retinal vascular disorders, second only to diabetic retinopathy in causes of visual loss [1]. There is a significant prevalence of this disorder in the elderly population, with an incidence of $1.3 \%$ in the aged 65 and older [2,3]. The fundus of a patient with ischemic CRVO gives an appearance of extensive blood, venous tortuosity, and capillary non-perfusion in all quadrants. Poor visual acuity at the onset predicts a poor outcome with little hope of visual recovery [4]. Further complications such as neovascular anterior
*Corresponding author: Lewis D Friedlander, Image Vision Surgery Center, 5505 Roswell RD, Atlanta GA, USA, Tel: 404-949-0049; E-mail: iccsurgery@aol.com

Received December 31, 2014; Accepted February 27, 2015; Published March 01,2015

Citation: Friedlander LD (2015) New Methods of Diagnosis and Treatment of Ophthalmic Artery Stenosis in Patients with Ischemic Central Retinal Vein Occlusions. J Vasc Med Surg 3: 190. doi:10.4172/2329-6925.1000190

Copyright: $\odot 2015$ Friedlander LD. This is an open-access article distributed unde the terms of the Creative Commons Attribution License, which permits unrestricted use, distribution, and reproduction in any medium, provided the original author and source are credited. 
Citation: Friedlander LD (2015) New Methods of Diagnosis and Treatment of Ophthalmic Artery Stenosis in Patients with Ischemic Central Retinal Vein Occlusions. J Vasc Med Surg 3: 190. doi:10.4172/2329-6925.1000190

segment changes can occur later, worsening the prognosis [5]. The prognosis for long-term outcome is extremely poor and no consistently effective treatment of ischemic CRVO has been reported [6-9].

Binocular Fundus Reflectometry (B.F.R.) is a technique which gives a simultaneous bilateral wash through perfusion curve of each fundus following the intravenous injection of a small bolus of dye [10] (Figure 1). The simultaneous measurements of arrival, filling, peak and runoff for each eye are generated in curves which can be consistently reproduced and analyzed. The use of this technology can be quantified similar to the use of Indocyanine Green dye, used in the measurement of pulmonary circulation [11]. B.F.R. is a measurement of perfusion which is evaluating mostly choroidal flow (Figure 2). B.F.R. curves have been previously correlated in individuals with normal angiography and in patients during intra-operative carotid surgery where exact vessel diameter was correlated with perfusion curves [12] (Figure 3 ). These curves showed signs of low flow before direct intra-arterial lumen pressure changes indicated decrease. We have also previously compared B.F.R. to O.D.M. and O.P.G. and found it to be more sensitive in detecting ophthalmic artery and inaccessible carotid disease. In this group of patients where retinal vascular occlusive disease was the presenting feature, we found B.F.R. correlated well with diagnosis of significant vascular disease of the ophthalmic artery or carotid artery (Figures 4-7). In the arteriographic evaluation of patients with ischemic visual loss it is important to closely examine the ophthalmic artery filling

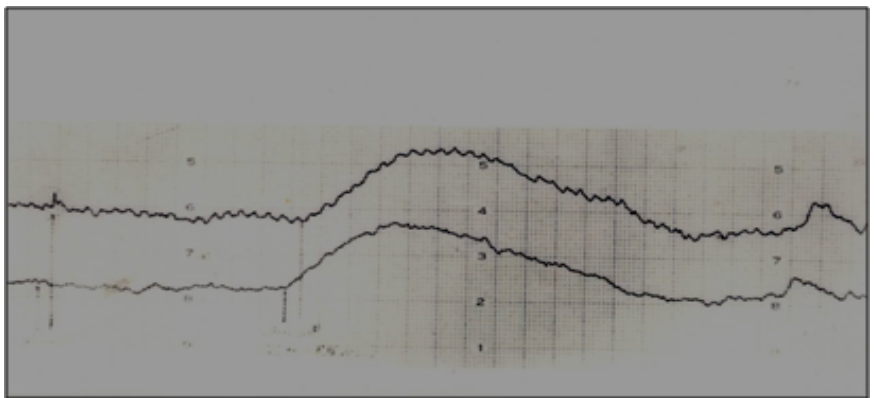

Figure 1: Example of a normal human reflectogram. The upper curve on the far left shows a spike, indicating the point of injection into the vein. The arrival is symmetric and clear uptake is seen with a rapid and defined peak with a slightly slower runoff on the down curve and there is even a clear recycle curve for each eye on the far right. The large arrow indicates injection point of dye and the small arrow indicates the arrival of bolus.

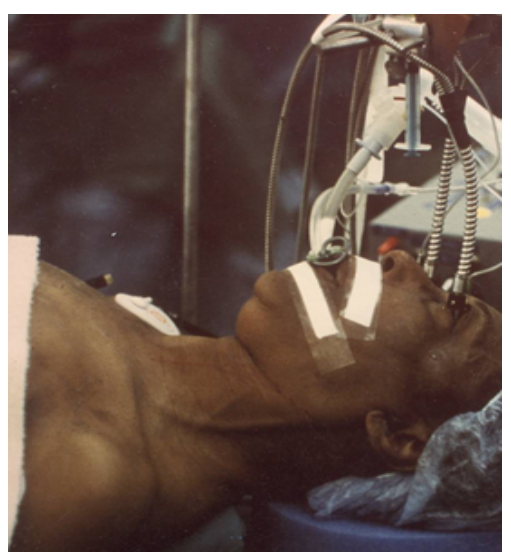

Figure 2: Patient undergoing carotid surgery has the lens apparatus in each eye in preparation for intra-operative measurements.

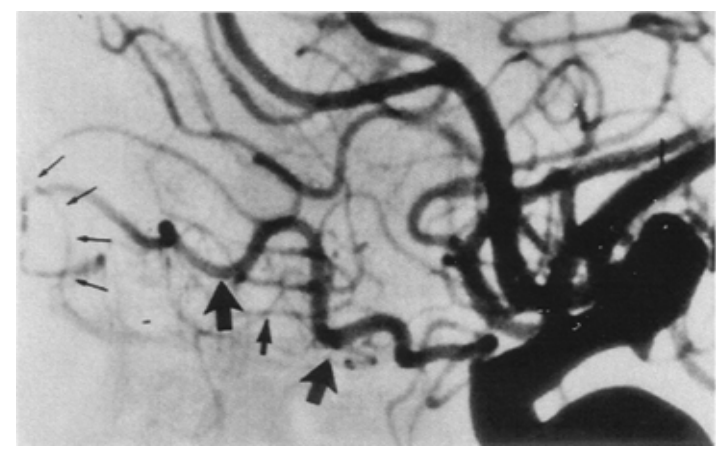

Figure 3: Normal arteriogram shown in this example, which exhibits filling of the main trunk with a gradual tapering and branching of the lacrimal, supraorbital and supra-trochlear. The choroidal blush is shown with a full and early filling.

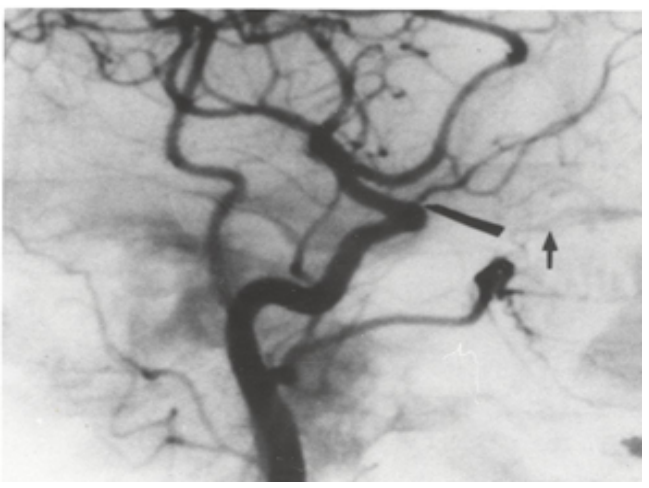

Figure 4: The arteriogram of patient \#1 shows a large arrow with almost complete occlusion of the ophthalmic artery at the takeoff of the siphon. The smaller arrow shows only a faint blush of the mid-ophthalmic artery with no distal filling.

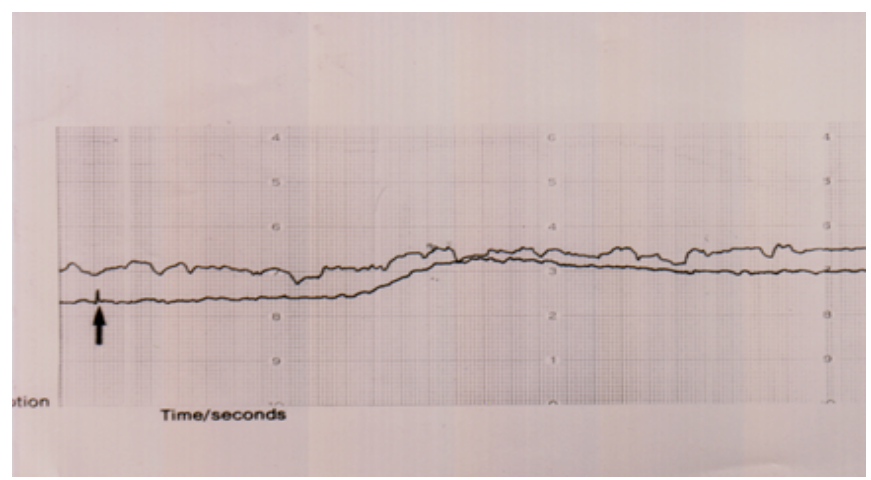

Figure 5: Patient \#2 reflectogram. The upper curve (right eye) shows minimal signal change, while the left eye lower curve shows normal arrival, filling and runoff. The large arrow shows point of injection.

sequence with selected magnification and subtraction views. Often, significant filling defects of the ophthalmic artery will go undetected in standard angiographic views that do not include subtraction and magnification. Although these associated findings do not prove cause and effect, the presence of ocular hypoperfusion as shown by B.F.R. in association with retinal vascular disease may justify angiographic investigation in some patients (Figures 8-10). 
Citation: Friedlander LD (2015) New Methods of Diagnosis and Treatment of Ophthalmic Artery Stenosis in Patients with Ischemic Central Retinal Vein Occlusions. J Vasc Med Surg 3: 190. doi:10.4172/2329-6925.1000190

Page 3 of 9

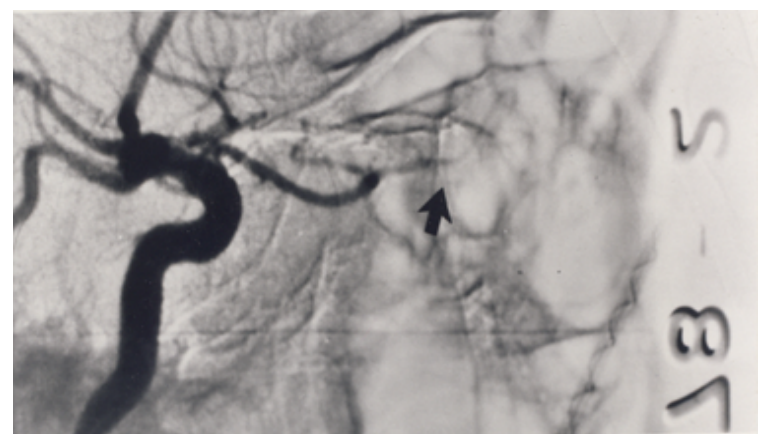

Figure 6: Right arteriogram of patient \#2 shows abrupt occlusion of the mid ophthalmic artery. No distal filling. The arrow shows point of abrupt arterial occlusion.

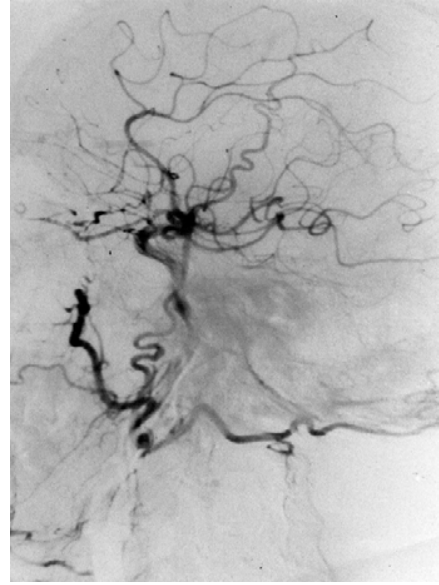

Figure 7: Left arteriogram shows mid-orbital arterial narrowing at the arrow and no distal filling, with an anomalous distal loop.

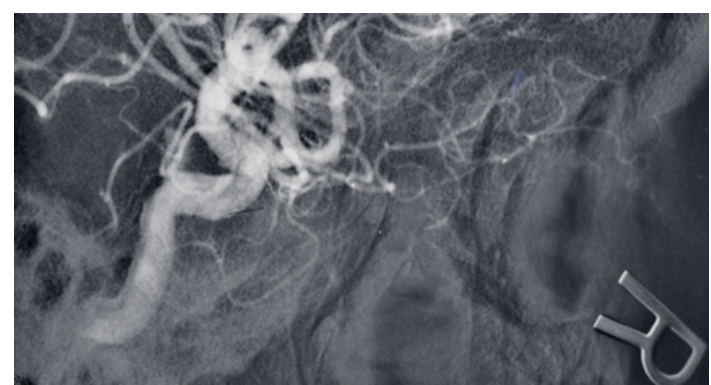

Figure 8: The right arteriogram shows severe narrowing of the midophthalmic artery with minimal distal filling.

\section{Materials and Methods}

Patients with the clinical diagnosis of ischemic central retinal vein occlusion disorders were referred to the Ocular Vascular Laboratory for determinations of ocular blood flow (Figures 11-14). All patients had ESR, CBC, RF, ANA, lipids, homocystene levels, thyroid profile, C-reactive Protein, RPR and FTA. Patients also had evaluations to rule out Polycythemia, Lymphoma, Leukemia, Activated Protein C, lupus, Proteins S, Multiply Myeloma, Syphilus, and Sarcoid. All patients had testing to rule out, myocardial ischemia, abnormal blood pressures and, uncontrolled diabetes. Ocular exams ruled out myopia, abnormal intraocular pressure, corneal abnormalities, krukenburg spindles, synechiae, angle closure, AVMs, Drusen and glaukomflecken. No patient had evidence of conjunctivitis, blepharitis, or chalazion. No patient had Irvine Gass Syndrome (Figures 15-18).

All patients had a non-contrast CT of the head. All patients had negative history for previous ocular infections including Toxoplasmosis and Herpes. Non-invasive testing of patients included evaluations of ocular perfusion by binocular fundus reflectometry (B.F.R.), measurements of ocular pulse pressure by ophthalmodynomoetry (O.D.M), occulopneumoplethysmography (O.P.G.) and fluorescein angiography. All patients underwent carotid ultrasound. Patients selected for this study met the criteria of clinical ischemic central retinal vein occlusion based on presentation of painless sudden visual

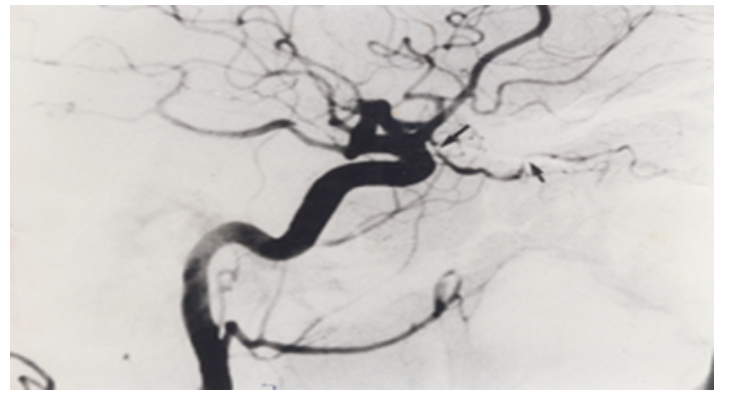

Figure 9: Right arteriogram shows severe narrowing and minimal dista filling. Arrow shows severe stenosis.

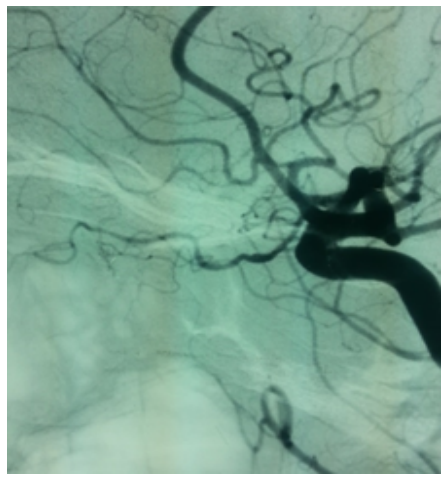

Figure 10: Arteriogram of left orbit shows similar pattern to right side with distal occlusion.

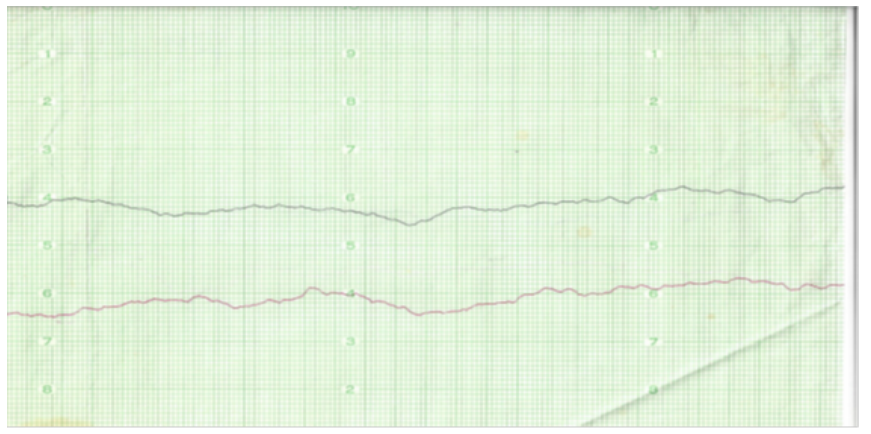

Figure 11: No definite flow curve for left or right eye. Flatline. 
Citation: Friedlander LD (2015) New Methods of Diagnosis and Treatment of Ophthalmic Artery Stenosis in Patients with Ischemic Central Retinal Vein Occlusions. J Vasc Med Surg 3: 190. doi:10.4172/2329-6925.1000190

Page 4 of 9

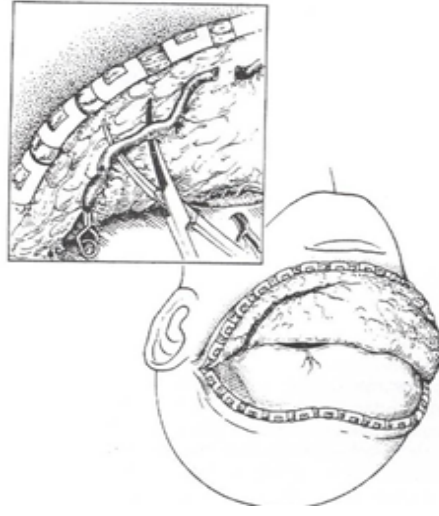

Figure 12: Use of coronal flap with sub galeal plane dissection to expose the supraorbital foramen and exit of the artery onto the flap. The superficial temporal artery is then carefully dissected from the flap to its pre-auricular portion to provide as much free length as possible to lead into the orbit for direct anastamosis in an end-to-end fashion with the orbital branch of the ophthalmic artery after removal of the bony portion of the foramen.

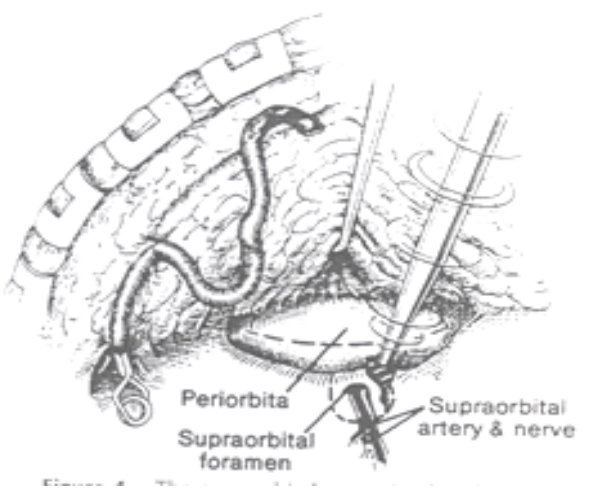

Figure 13: The bony portion of the foramen is removed with a high-speed drill while the neurovascular bundle is protected with a nerve hook.

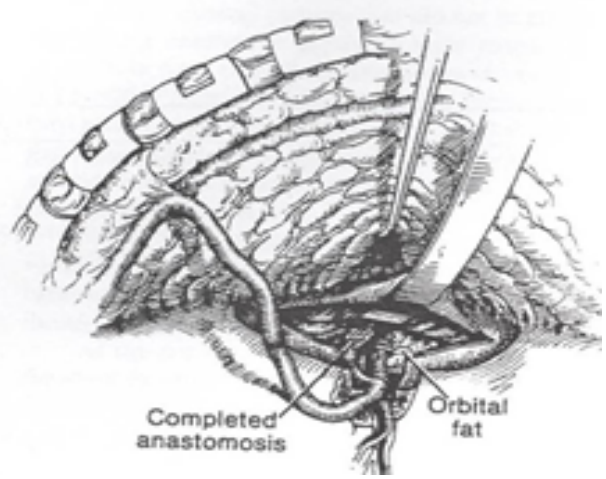

Figure 14: Completed end-to-end anastamosis in the superior orbit.

loss with a fundoscopic picture of dilated tortuous vein and extensive hemorrhages in all quadrants followed by fluorescein findings of extensive non perfusion for significantly greater than 10 disc diameters. Also in some cases there was relative afferent pupillary defect as well as cotton wool spots present (Figures 18-21).
B.F.R. is a non-invasive technique to measure ocular, and in particular, choroidal perfusion. Infrared light is directed to the fundus by special contact lenses through fiberoptic cables. The light reflected off the fundus passes back through the fiberoptic cables to a photodetector for each eye where it is measured and recorded constantly. The signal is transmitted through individual amplifiers and can then be transferred to a direct chart recorder and /or computer. Five cc. of a protein-bound green dye (Indocyanine-Green) is injected into an antecubital vein and absorbs some of the light as it passes through the choroidal and retinal vasculature. The change in light absorption that occurs over time as the dye passes through the ocular vasculature produces a dome shaped wash-through curve for each eye that can be used to analyze ocular perfusion.

Interpretation of B.F.R. was assisted by previous comparison with age-matched adults who underwent cerebral angiography and had a normal study. Ocular perfusion of each eye was determined by the following criteria: arrival time of the dye, filling (the upward slope

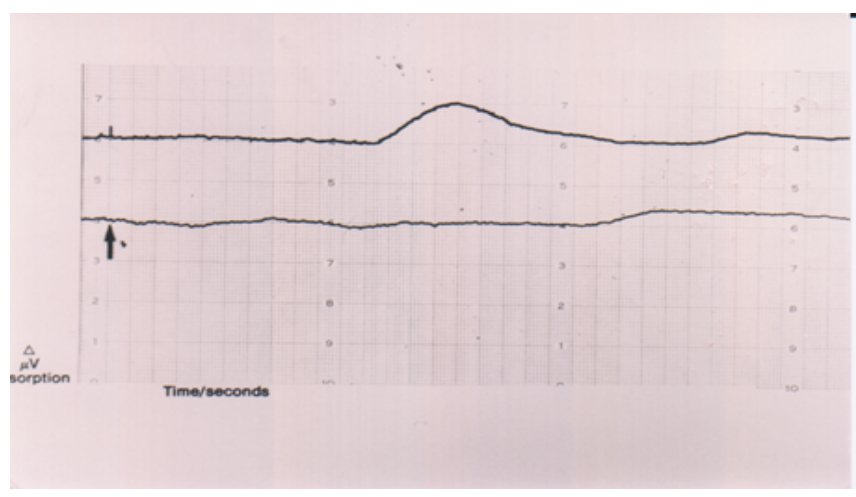

Figure 15: Post op, immediate post-operative flows showed dramatic improvement in the right side, correlating with significant improvement in visual acuity and visual function. The left signal shows dramatic improvement in perfusion, correlating with definite improvement in the left eye visual function.

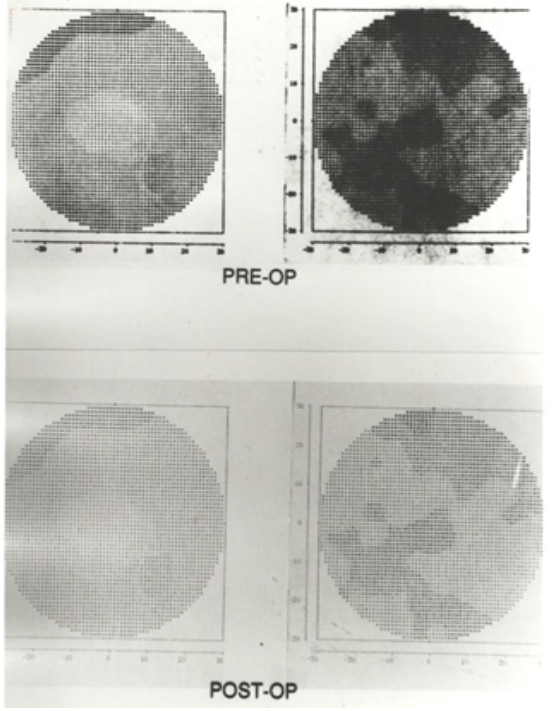

Figure 16: Pre-operative and post-operative visual fields show dramatic improvement in both eyes after unilateral (right) ophthalmic artery bypass. 
Citation: Friedlander LD (2015) New Methods of Diagnosis and Treatment of Ophthalmic Artery Stenosis in Patients with Ischemic Central Retinal Vein Occlusions. J Vasc Med Surg 3: 190. doi:10.4172/2329-6925.1000190

Page 5 of 9

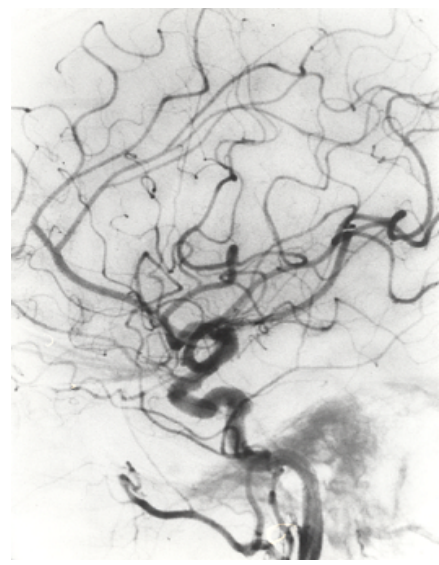

Figure 17: Left ophthalmic artery slow filling, no distal branches and no choroid blush.

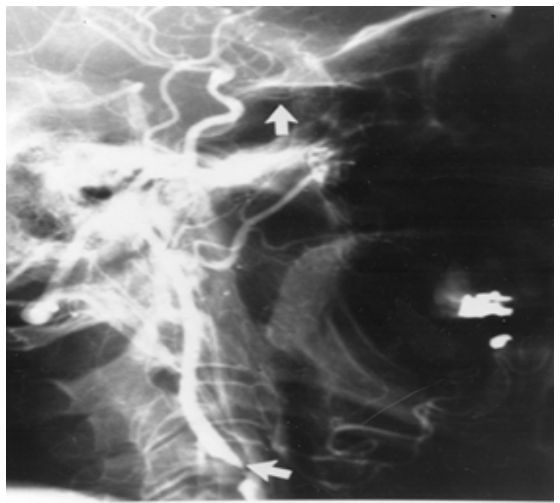

Figure 18: Right ophthalmic artery abrupt occlusion at the mid-orbit. Right $90 \%$ common carotid stenosis.
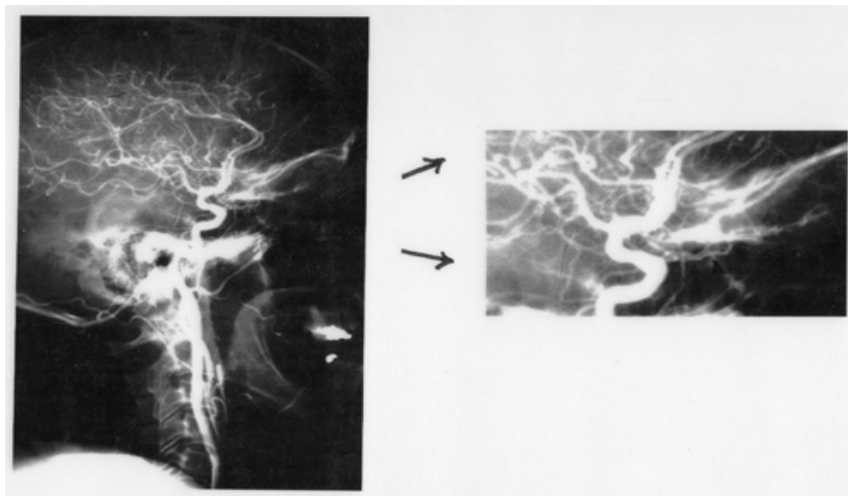

Figure 19: Right orbit after carotid surgery shows some improvement in flow, but still with high-grade occlusion of the ophthalmic artery.

of the curve), energy absorption change or peak filling (the highest voltage change of reflectance), and washout or runoff (the slope of the downward curve). Symmetry between the two sides was also assessed. Based on previous studies, the normal arrival time ranges from 8-14 seconds; beyond 14 seconds was considered abnormal, as was a difference in the arrival times of the two sides by greater than one second. The perfusion was analyzed by the appearance of the flow curve and abnormalities determined by asymmetry to the opposite eye or obvious deviations from the appearance of a normal trace. Although in these studies we did not attempt to quantify flow, extrapolations of volumes and curve areas can be applied to yield meaningful numbers. 1 The volume and reflectance of a globes vasculature completely filled with indocyanine greene dye can be calculated in animal studies and estimates in humans can give reproducible values. At the Emory University Ocular-Vascular Lab, over 150 B.F.R.'s were performed and 299 eyes evaluated in this manner with a 95\% correlation of abnormal perfusion curves and angiographically significant identifiable lesion of the carotid or ophthalmic artery.

Cerebral angiographic evaluation was directed to the cervical carotid, the intra-cavernous carotid, and the ophthalmic arteries. Magnified and subtracted films were routinely made. Abnormalities of angiographic filling included stenosis of the origin of the ophthalmic artery and unilateral absence of the ciliary complex $[13,14]$. Any variants present were noted. Filling of cerebral cortical branches before filling of the ophthalmic artery was considered abnormal. Appearance of the choroidal blush more than 1.5 seconds after filling of the carotid siphon also indicated poor ocular perfusion [15]. The ciliary complex vasculature was evaluated only from subtraction and magnification views.

\section{Results}

All nine patients had normal metabolic and cardiac evaluation as well as a normal CT scan of the brain and orbit. All patients in the study had abnormal reflectograms by BFR on the affected side. All patients showed definite evidence of abnormal orbital ophthalmic artery filling on the affected side that could explain poor inflow. In three of the nine cases there were significant ophthalmic artery lesions on the contralateral asymptomatic side. Three of the nine cases showed diffuse ophthalmic artery disease with slow or no choroidal filling and absence of distal vessel filling in either the ciliary complex or the lacrimal or supraorbital branches. The other six patients had clear focal ophthalmic artery lesions and evidence of poor distal filling. No variants were noted. The results of the presentations, evaluations, and arteriograms are summarized in the tables listed (Tables 1-9).

In the one patient who underwent ophthalmic artery bypass, presenting with bilateral ischemic CRVO, both the operated side and un-operated side had dramatic improvement in visual function

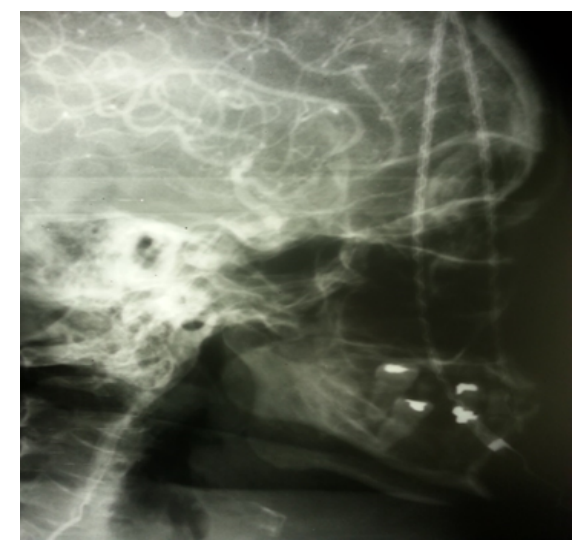

Figure 20: Right orbit arteriogram shows minimal filling and no choroid blush, even after delayed films. 
Citation: Friedlander LD (2015) New Methods of Diagnosis and Treatment of Ophthalmic Artery Stenosis in Patients with Ischemic Central Retinal Vein Occlusions. J Vasc Med Surg 3: 190. doi:10.4172/2329-6925.1000190

Page 6 of 9

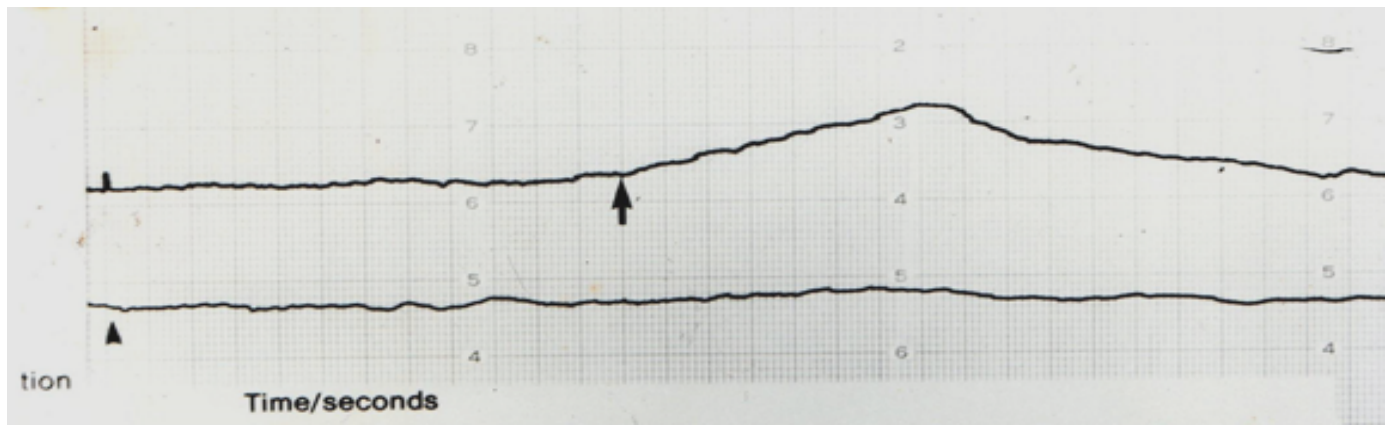

Figure 21: BFR readings show left (upper) flow with normal characteristics while the R (lower) signal is unreadable illustrati.

\begin{tabular}{|c|c|c|c|c|}
\hline Patient & Presentation/Past Medical History & $\begin{array}{l}\text { FA } \\
\text { OPG/ODM } \\
\text { Carotid Ultrasound }\end{array}$ & BFR & Arteriogram \\
\hline $\begin{array}{c}1 \\
65 \text { yr old } \\
\text { WF }\end{array}$ & $\begin{array}{l}\text { Presentation } \\
\text { Intermittent dimming of vision OD for several weeks. } \\
\text { Acute loss of vision OD } \\
\text { VA/ OD=HM. } \\
\text { Diffuse retinal hemorrhages. } \\
\text { DX Ischemic CRVO. Past history S/P Rt. Carotid } \\
\text { endarterectomy } 1 \text { yr. ago } \\
\text { OD relative afferent pupillary defect }\end{array}$ & $\begin{array}{l}\text { Non-Invasive } \\
\text { FA= Slow filling, slow run off } \\
\text { OPG/ODM=Negative } \\
\text { Carotid Ultrasound= Negative }\end{array}$ & $\begin{array}{l}\text { BFR } \\
\text { Rt (top curve) extreme delay } \\
\text { of arrival filling and run off. } \\
\text { Lt side (bottom curve) rapid } \\
\text { filling } 9 \text { seconds rapid arrival } \\
\text { and quick run off }\end{array}$ & $\begin{array}{l}\text { Cerebral } \\
\text { Angiogram } \\
\text { Rt. Only trace visualization of Rt. } \\
\text { OA. No choroid blush, no distal } \\
\text { branches filling. } \\
\text { Normal carotid artery. } \\
\text { Lt Normal Normal carotid artery. }\end{array}$ \\
\hline
\end{tabular}

Table 1: Description of Patient 1.

\begin{tabular}{|c|l|l|l|}
\hline Patient & Presentation/ Past Medical History & $\begin{array}{l}\text { FA } \\
\text { OPG/ODM } \\
\text { Carotid Ultrasound }\end{array}$ & BFR \\
\hline 2 & $\begin{array}{l}\text { Mild blurring in OD } \times 3 \text { mos. Progressive onset } \\
\text { visual loss OD } \times 1 \text { day. VA OD 20/400 PERRLA } \\
\text { Diffuse retinal hemorrhages } \\
\text { Dx. Ischemic CRVO } \\
\text { PMH-hypertension }\end{array}$ & $\begin{array}{l}\text { Rt Side-Poor filling of retinal arteries } \\
\text { in all quadrants. } \\
\text { OPG/ODM=Normal } \\
\text { Poor choroidal filling. Retinal and } \\
\text { choroidal filling significantly delayed. } \\
\text { No retrograde filling. }\end{array}$ & $\begin{array}{l}\text { Rt. No recordable } \\
\text { signal. }\end{array}$ \\
BM & Lt. normal arrival 10 \\
sec. & $\begin{array}{l}\text { Lt. Carotid and ophthalmic artery } \\
\text { normal. } \\
\text { Rt. Severe stenosis of mid } \\
\text { ophthalmic artery. No fine vessel } \\
\text { filling. No choroid blush. } \\
\text { (Figure 8) }\end{array}$ \\
\hline
\end{tabular}

Table 2: Description of Patient 1.

\begin{tabular}{|c|c|c|c|c|}
\hline Patient & Presentation/ Past Medical history & $\begin{array}{l}\text { FA } \\
\text { OPG/ODM } \\
\text { Carotid } \\
\text { Ultrasound }\end{array}$ & BFR & Arteriogram \\
\hline $\begin{array}{c}3 \\
56 \text { YO } \\
\text { WM }\end{array}$ & $\begin{array}{l}\text { Intermittent visual loss } \\
\text { OD x several weeks. VA OD } 20 / 40>20 / 400 \\
\text { Relative afferent pupillary defect } \\
\text { Fundus- marked engorgement retinal veins. Scattered } \\
\text { hemorrhage mid periphery. } \\
\text { Dx CRVO } \\
\text { PMH hypertension. Previous sudden visual loss following } \\
\text { CAGB } 3 \text { yrs ago. }\end{array}$ & $\begin{array}{l}\text { Poor filling. } \\
\text { Arterial leak } \\
\text { No capillary } \\
\text { obliteration. } \\
\text { OPG/ODM-Normal } \\
\text { Carotid } \\
\text { Ultrasound-Normal }\end{array}$ & $\begin{array}{l}\text { Rt. Slow Arrival } 16 \text { sec. } \\
\text { Slow filling. Slow runoff } \\
\text { Lt. slow arrival } 16 \text { sec. } \\
\text { Slow filling, poor runoff }\end{array}$ & $\begin{array}{l}\text { Rt. Abrupt stenosis of ophthalmic artery at mid } \\
\text { portion. } \\
\text { No distal filling } \\
\text { Carotid siphon narrowing moderate. } \\
\text { Lt. narrowing of distal ophthalmic artery with no } \\
\text { ciliary filling. Normal carotid } \\
\text { (Figure 6) }\end{array}$ \\
\hline
\end{tabular}

Table 3: Description of Patient 3.

immediately after surgery that was sustained. On fundoscopic exam the venous bleeds and swelling improved within days and the flourescein angiograms as well as the BFR improved in flow characteristics dramatically. This patient's results are included in the tables (patient number 5).

\section{Discussion}

Ischemic CRVO is a devastating disorder with poor prognosis. Modern techniques of medical and surgical approaches to CRVO have given minimal improvement $[16,17]$. The pathogenesis of this disorder remains unclear, and has been in debate for some time. A number of risk factors of been associated with CRVO which include: hypertension, diabetes, atherosclerosis, glaucoma, syphilis, sarcoidosis, vasculitis, increased intra-orbital or intraocular pressure, hyphema, hyper viscosity syndromes (multiple myeloma, Waldenstrom's acroglobulinemia, and leukemia), high homocysteine levels, sickle cell, and HIV [18]. The standard evaluation of ischemic CRVO does not include detailed cerebral angiography [19]. In previous cases studied with cerebral angiography, no consistent attention to the details of orbital filling have been reported. Even the use of digital subtraction angiography is insufficient to properly evaluate the orbit 
Citation: Friedlander LD (2015) New Methods of Diagnosis and Treatment of Ophthalmic Artery Stenosis in Patients with Ischemic Central Retinal Vein Occlusions. J Vasc Med Surg 3: 190. doi:10.4172/2329-6925.1000190

Page 7 of 9

\begin{tabular}{|c|c|c|c|c|}
\hline Patient & Presentation / Past Medical History & $\begin{array}{l}\text { FA } \\
\text { OPG/ODM } \\
\text { Carotid Ultrasound }\end{array}$ & BFR & Arteriogram \\
\hline $\begin{array}{c}4 \\
63 \text { YO } \\
\text { BM } \\
4\end{array}$ & $\begin{array}{l}\text { Several days intermittent visual blurring OD. VA OD } \\
20 / 60->20 / 400 . \\
\text { PERRLA } \\
\text { Tortuosity of all retinal veins. } \\
\text { Diffuse venous hemorrhages Dx ischemic CRVO }\end{array}$ & $\begin{array}{l}\text { FA- Rt eye Poor filling retinal artery in all } \\
\text { quadrants. } \\
\text { Significant delay of choroidal filling. } \\
\text { OPG/ODM-Normal } \\
\text { Carotid Ultrasound- Normal }\end{array}$ & $\begin{array}{l}\text { BFR- Rt slow } \\
\text { arrival(bottom curve) } \\
24 \text { seconds } \\
\text { Slow run off } \\
\text { Lt. (bottom curve) } \\
\text { normal arrival } 9 \\
\text { seconds } \\
\text { good filling } \\
\text { good run off }\end{array}$ & $\begin{array}{l}\text { Rt. Severe narrowing of mid OA } \\
\text { Delayed choroid blush } \\
\text { No visible ciliary arteries } \\
\text { Lt.Normal }\end{array}$ \\
\hline
\end{tabular}

Table 4: Description of Patient 4.

\begin{tabular}{|c|c|c|c|c|}
\hline Patient & Presentation/ Past Medical History & $\begin{array}{l}\text { FA } \\
\text { OPG/ODM } \\
\text { Carotid Ultrasound }\end{array}$ & BFR & Arteriogram \\
\hline $\begin{array}{c}5 \\
62 \text { YO } \\
\text { BM } \\
\text { Pre- Bypass }\end{array}$ & $\begin{array}{l}\text { Acute visual loss OD. } \\
\text { VA OD- LP afferent papillary defect } \\
\text { Blood and thunder in all } 4 \text { quadrants } \\
\text { General visual field loss } \\
\text { Visual acuity OS } \\
20 / 200 \\
\text { Decreased visual fields. Fundus exam blood and } \\
\text { thunder appearance, all quadrants } \\
\text { Dx ischemic CRVO OU } \\
\text { PMH diabetes with previously well controlled } \\
\text { glucose and mild diabetic retinal changes }\end{array}$ & $\begin{array}{l}\text { FA-Slow filling slow run off } \\
\text { OPG/ODM=Negative } \\
\text { Carotid Ultrasound=Negative }\end{array}$ & $\begin{array}{l}\text { Lt. non recordable signal } \\
\text { Rt. } \\
\text { non-recordable } \\
\text { signal }\end{array}$ & $\begin{array}{l}\text { Almost complete occlusion of } \\
\text { proximal portion of the Rt ophthalmic } \\
\text { artery } \\
\text { Poor filling of the Lt distal ophthalmic } \\
\text { artery }\end{array}$ \\
\hline
\end{tabular}

Table 5: Description of Patient 5.

\begin{tabular}{|c|c|c|c|c|}
\hline Patient & Presentation/ Past Medical History & $\begin{array}{l}\text { FA } \\
\text { OPG/ODM } \\
\text { Carotid Ultrasound }\end{array}$ & BFR & Arteriogram \\
\hline $\begin{array}{c}6 \\
64 \text { YO } \\
\text { WF }\end{array}$ & $\begin{array}{l}\text { Sudden severe loss of central vision VA OS } \\
=20 / 400 \\
\text { Macular edema } \\
\text { Blood and thunder retina } \\
\text { Dx ischemic CRVO } \\
\text { Lt afferent pupillary defect }\end{array}$ & $\begin{array}{l}\text { Lt eye severe reduction in } \\
\text { choroid filling } \\
\text { OPG/ODM-Normal } \\
\text { Carotid Ultrasound-Normal }\end{array}$ & $\begin{array}{l}\text { Lt. (bottom curve) minimal filling } \\
\text { Severe delay in arrival } \\
\text { Rt (upper curve) normal arrival } 9 \text { seconds } \\
\text { Filling and run off- normal }\end{array}$ & $\begin{array}{l}\text { Lt. Distal ophthalmic artery, severe } \\
\text { narrowing occlusion with no ciliary } \\
\text { filling } \\
\text { Rt-normal }\end{array}$ \\
\hline
\end{tabular}

Table 6: Description of Patient 6.

\begin{tabular}{|c|l|l|l|}
\hline Patient & Presentation/ Past Medical History & $\begin{array}{l}\text { FA } \\
\text { OPG/ODM } \\
\text { Carotid Ultrasound }\end{array}$ & BFR \\
\hline 7 & $\begin{array}{l}\text { Several days of progressive visual loss in Rt eye } \\
\text { Fundus exam shows venous tortuosity and hemorrhages in all }\end{array}$ & FA- Rt decreased perfusion in all quadrants \\
68 YO & $\begin{array}{l}\text { quadrants. } \\
\text { WM }\end{array}$ & OPacular edema & OPG/ODM-Normal significant decrease in \\
Visual acuity hand motion only & Carotid Ultrasound-Normal & Lt. eye normal \\
\hline
\end{tabular}

Table 7: Description of Patient 7.

\begin{tabular}{|c|l|l|l|l|}
\hline Patient & Presentation/ Past Medical History & $\begin{array}{l}\text { FA } \\
\text { OPG/ODM } \\
\text { Carotid Ultrasound }\end{array}$ & BFR & Arteriogram \\
\hline $\begin{array}{c}82 \text { YO } \\
\text { WM }\end{array}$ & $\begin{array}{l}\text { Sudden onset vision loss Lt eye } \\
\text { Visual acuity LP only } \\
\text { Rt. Eye asymptomatic }\end{array}$ & Slow filling Lt eye & No signal Lt eye & LPG/ODM- Normal narrowing of distal ophthalmic artery poor distal \\
filling & Rt- slow filling & Rt orbit- poor distal filling \\
\hline
\end{tabular}

Table 8: Description of Patient 8.

where significant pathology may be present [20]. The resolution and filling detail of smaller vessels is not adequate to compare to standard angiography. No study we reviewed directed any attention to the details of ophthalmic artery filling in ischemic central retinal vein occlusions.

BFR curves have been previously correlated in individuals with normal angiography and in patients during intra-operative carotid surgery where exact vessel diameter and vessel pressures were correlated with perfusion curves.

These curves showed signs of low perfusion before direct intra-arterial pressure changes indicated lumen decrease. We have also compared BFR to Ophthalmodynamometry (ODM) and Occulopneumoplethysmography (OPG) and found it to be more 


\begin{tabular}{|c|c|c|c|c|}
\hline Patient & Presentation/ Past Medical History & $\begin{array}{l}\text { FA } \\
\text { OPG/ODM } \\
\text { Carotid Ultrasound }\end{array}$ & BFR & Arteriogram \\
\hline $\begin{array}{l}9 \\
64 \mathrm{YO} \\
\mathrm{BM}\end{array}$ & $\begin{array}{l}\text { Sudden painless visual loss Lt eye } \\
\text { LP only } \\
\text { Macular Edema } \\
\text { Cotton wool spots }\end{array}$ & $\begin{array}{l}\text { Lt extremely slow filling } \\
\text { OPG/ODM- Normal } \\
\text { Carotid Ultrasound- Normal }\end{array}$ & $\begin{array}{l}\text { Lt no signal on affected } \\
\text { side } \\
\text { Rt- Normal }\end{array}$ & $\begin{array}{l}\text { Lt normal ophthalmic artery } \\
\text { No choroid blush } \\
\text { No ciliary filling } \\
\text { Rt-Normal }\end{array}$ \\
\hline
\end{tabular}

Table 9: Description of Patient 9

sensitive in detecting ophthalmic artery and inaccessible carotid disease. In this group of patients with various forms of retinal vascular disease as the presentation, BFR indicated low perfusion by delayed arrival, prolonged filling, and slow run-off.

Studies using Doppler signal, have shown evidence that ophthalmic artery blood flow was decreased in cases where ischemic CRVO was present $[21,22]$. However, some of the studies were inconclusive. The use of Doppler to evaluate the orbital and retinal vessels may be a valuable tool if angiographic correlations were available and properly interpreted to diagnose ophthalmic artery disease. New techniques for enhanced imaging of the choroid will certainly add to the understanding of the pathophysiology [23]. However, these techniques should be correlated with assessment of the ophthalmic artery. Most of these cases had a definite focal proximal ophthalmic artery narrowing which could be amenable to bypass. The selective application and indication of orbital revascularization is just beginning to be evaluated. In our case where revascularization was performed, a dramatic improvement occurred in the fundus findings, visual fields, visual acuity, and fluorescein angiography of the operated side and the non-operated side. This phenomenon could be explained by the recruitment of collateral flow from one ophthalmic artery to the other through ethmoidal perforators. We have observed and documented this occurrence in other cases where revascularization was used for the treatment of ischemic optic neuropathy. The details of orbital angiography dictate consideration of intervention in these cases [24]. In the setting of progressive visual loss and deterioration of the retina, a focal proximal ophthalmic lesion creates a setting where there may be an opportunity to reroute the flow through one of the distal branches by creating a reverse flow situation. In a case where there is diffuse disease of the ophthalmic artery, the use of distal revascularization would be questionable. This report gives BFR findings and curve analysis and careful analysis of ophthalmic artery arteriograms in a group of patients with retinal vascular disease. When compared with other non-invasive technology, based on pressure or pulse-pressure changes, BFR seems to be more sensitive for detecting occlusive disease of the ophthalmic vessels. Investigators who wish to look at the possibility of vascular disease of the ophthalmic artery as a cause for retinal vascular disorders are advised to carefully study the normal angiograms of orbit filling because often only subtle changes may be present. With practice, the details of this important region on angiography will become familiar.

The evaluation of other organ systems including the brain, heart, lungs, intestines, kidneys, and extremities have a strict protocol to evaluate signs of ischemia by angiography. Based on the findings of a large number of significant ophthalmic artery lesions in association of ischemic retinal syndromes. It will become increasingly important to evaluate the orbital arteries in evaluating ischemic central retinal vein occlusion. This study was supported in part by an unrestricted grant to the Department of Ophthalmology from Research to Prevent Blindness, Inc, New York, and a grant to Dr. Friedlander from the National Society for the Prevention of Blindness. This study was approved by the NIH and the Human Investigations Committee at Emory University.

\section{References}

1. Alasil T, Lee N, Keane P, Sadda S (2009) Central retinal vein occlusion: a case report and review of the literature. Cases J 2: 7170.

2. [No authors listed] (1997) Natural history and clinical management of centra retinal vein occlusion. The Central Vein Occlusion Study Group. Arch Ophthalmol 115: 486-491.

3. Mohamed Q, Mclntosh RL, Saw SM, Wong TY (2007) Interventions for central retinal vein occlusion: an evidence-based systematic review. Ophthalmology 114: $507-519,524$

4. Klein R, Moss SE, Meuer SM, Klein BE (2008) The 15-year cumulative incidence of retinal vein occlusion: the Beaver Dam Eye Study. Arch Ophthalmol 126: 513-518.

5. [No authors listed] (1993) Baseline and early natural history report. The Central Vein Occlusion Study. Arch Ophthalmol 111: 1087-1095.

6. Zegarra H, Gutman FA, Conforto J (1979) The natural course of central retinal vein occlusion. Ophthalmology 86: 1931-1942

7. Quinlan PM, Elman MJ, Bhatt AK, Mardesich P, Enger C (1990) The natural course of central retinal vein occlusion. Am J Ophthalmol 110: 118-123.

8. Hayreh SS, Rojas P, Podhajsky P, Montague P, Woolson RF (1983) Ocular neovascularization with retinal vascular occlusion-III. Incidence of ocular neovascularization with retinal vein occlusion. Ophthalmology 90: 488-506.

9. Green WR, Chan CC, Hutchins GM, Terry JM (1981) Central retinal vein occlusion: a prospective histopathologic study of 29 eyes in 28 cases. Trans Am Ophthalmol Soc 79: 371-422.

10. Friedlander LD, Barrow DL, Crenshaw SM, Haygood WF, Wood JH (1998) Binocular fundus reflectometry as an indicator of ocular perfusion system design and experimental results and clinical studies. Journal of Neurovascular Disease 3:81-87.

11. Slutsky RA, Bhargava V, Higgins CB (1983) Pulmonary circulation time: Comparison of mean, median, peak, and onset ( appearance ) values using indocyanine green and first-transit radionuclide techniques. Am Heart J 106: $41-45$

12. Friedlander LD, Barrow DL, BaKay RA (1986) New methods for diagnosis and treatment of ischemic visual loss. Acta XXV Concilium Ophthalmologicum Proceedings of the XXVth International Congress of Ophthalmology held in Rome, Italy 4-10: 384-403.

13. Lloyd GA (1969) A technique for arteriography of the orbit. $\mathrm{Br} \mathrm{J}$ Radiol 42 252-255.

14. Schurr PH (1951) Angiography of the normal ophthalmic artery and choroidal plexus of the eye. Br J Ophthalmol 35: 473-478.

15. Handel SF, Stargardter FL, Glickman MG, Newton TH (1973) Frequency of the ocular choroid blush during arteriography. Neuroradiology 6: 50-55.

16. Sharma A, D'Amico DJ (2004) Medical and surgical management of central retinal vein occlusion. Int Ophthalmol Clin 44: 1-16.

17. Taneja N, Mathai A (2006) Retinal blood flow and macular edema after radia optic neurotomy for central retinal vein occlusion. Am J Ophthalmol 142: 710.

18. O'Mahoney PR, Wong DT, Ray JG (2008) Retinal vein occlusion and traditional risk factors for atherosclerosis. Arch Ophthalmol 126: 692-699.

19. Hayreh SS (2005) Prevalent misconceptions about acute retinal vascular occlusive disorders. Prog Retin Eye Res 24: 493-519. 
Citation: Friedlander LD (2015) New Methods of Diagnosis and Treatment of Ophthalmic Artery Stenosis in Patients with Ischemic Central Retinal Vein Occlusions. J Vasc Med Surg 3: 190. doi:10.4172/2329-6925.1000190

Page 9 of 9

20. Campo RV, Aaberg TM (1983) Digital subtraction angiography in the diagnosis of retinal vascular disease. Am J Ophthalmol 96: 632-640.

21. Keyser BJ, Flaharty PM, Sergott RC, Brown GC, Lieb WE, et al. (1994) Color Doppler imaging of arterial blood flow in central retinal vein occlusion. Ophthalmology 101: 1357-1361.

22. Ozbek Z, Saatci AO, Durak I, Kaynak S, Ergin MH, et al. (2002) Colour Doppler assessment of blood flow in eyes with central retinal vein occlusion. Ophthalmologica 216: 231-234.
23. Tsuiki E, Suzuma K, Ueki R, Maekawa $Y$, Kitaoka T (2013) Enhanced depth imaging optical coherence tomography of the choroid in central retinal vein occlusion. Am J Ophthalmol 156: 543-547.

24. Friedlander LD, Barrow DL, Bakay RA (1995) Microsurgical revascularization of the ophthalmic artery. Skull Base Surg 5: 191-198. 